\title{
The effect of the social and physical environment on children's independent mobility to neighborhood destinations
}

Brief running head: Independent mobility to neighborhood destinations.

Manuscript type: Original Research.

Key words: Child, Independent travel, Built environment, Social environment.

Abstract word count: 200.

Main text word count: 24 pages; 5713 words (excluding abstract and title page).

Date of manuscript submission: $5^{\text {th }}$ June 2014.

Date of manuscript revision submission: 27 ${ }^{\text {th }}$ October 2014. 
1 Abstract

2 Background: Relationships between context-specific measures of the physical and social

3 environment and children's independent mobility to neighborhood destination types were

4 examined.

5

6 Methods: Parents in RESIDE’s 4th survey reported whether their child (8-15 years; n=181) was

7 allowed to travel without an adult to school, friend's house, park and local shop. Objective physical

8 environment measures were matched to each of these destinations. Social environment measures

9 included neighborhood perceptions and items specific to local independent mobility.

11 Results: Independent mobility to local destinations ranged from 30-48\%. Independent mobility to a local park was less likely as the distance to the closest park (small and large size) increased and less likely with additional school grounds $(\mathrm{p}<0.05)$. Independent mobility to school was less likely as the distance to the closest large park increased and if the neighborhood was perceived as unsafe $(\mathrm{p}<0.05)$. Independent mobility to a park or shops decreased if parenting social norms were unsupportive of children's local independent movement $(\mathrm{p}<0.05)$.

Conclusions: Independent mobility appears dependent upon the specific destination being visited and the impact of neighborhood features varies according to the destination examined. Findings highlight the importance of access to different types and sizes of urban green space for children's independent mobility to parks. 


\section{Introduction}

Children's independent mobility, defined as the license and ability to move around the neighborhood unaccompanied by adults, ${ }^{1}$ is increasingly being investigated due to a strong association with beneficial health behaviors, such as active travel and physical activity. ${ }^{2,3}$ Moreover, independent mobility provides additional psychosocial benefits by allowing children the opportunity to socially interact with friends and the local community. ${ }^{2,4}$ Independently mobile children are also more likely to develop mapping and way-finding abilities ${ }^{5,6}$ and learn how to interact with and navigate their local built and natural environments. ${ }^{7}$ Despite the many benefits of independent mobility, studies from various countries report a rapid decline in the 1970-1980’s to the current low levels. ${ }^{2,8-10}$ For example, since 2002 only about $40 \%$ of UK children 7-13 years have been allowed to commute to school unaccompanied. ${ }^{11}$ Children are increasingly now driven to school and leisure activities. ${ }^{8,11}$ This trend is partly attributed to an increased number of cars in households, a rise in households where both parents work, increased distances between home and school, and a shift from free play in the neighborhood to organized activities outside the neighborhood where children are escorted, predominantly by car. ${ }^{8}$

A number of demographic, social and physical environment factors are associated with children's independent mobility. More independent mobility appears to be strongly associated with being male and older (vs. female and younger) $)^{1,4,6,12}$ and having siblings and friends. ${ }^{4,13-15}$ Parents oversee their children's travel behavior ${ }^{16}$ and thus their perceptions of the social and physical environment impact on their children's freedom to travel independently. "Traffic danger” and "stranger danger” are two main reasons why parents restrict their child's independent mobility. ${ }^{1,8,15}$ However, children living in neighborhoods with well connected, low traffic streets have higher overall independent mobility. ${ }^{17}$ Broader community social constructs such as collective efficacy (i.e., mutual trust and the shared willingness of residents to intervene for the public good), ${ }^{18}$ and perceptions of social and 
physical disorder (e.g., vandalism, graffiti, evidence of drug and alcohol use) may also play a role in parent's willingness to grant their children mobility licenses. ${ }^{15}$ To date, studies of the environmental correlates of independent mobility have been limited by the lack of objective and context-specific measures of the physical and social environment. ${ }^{6,19}$

The majority of studies of children's independent mobility focus on one type of destination, travel to or from school. ${ }^{2}$ There are fewer studies examining children's independent mobility to leisure activities (e.g., going to the park, visiting friends) ${ }^{8}$ and destinations such as local shops. ${ }^{20}$

Promoting active travel to these types of activities has been identified as a viable strategy to increase children's physical activity. ${ }^{21}$ A recent study reported that the physical environment was correlated with non-school walking journeys (e.g., friends’ houses, shops, parks, places of worship and clubs) but not walking to school, highlighting that the physical environment may be more important for discretionary journeys compared with school journeys. ${ }^{22,23}$ There appear to be no studies to date that have investigated neighborhood factors associated with independent mobility to specific destination types, nor how the quality of neighborhood environments influences the type of destination a child visits independently. This research requires the use of context-specific measures of the behavior and the environments ${ }^{19}$ and is important for a consistent evidence base to inform the development of more targeted independent mobility interventions. The aim of this study was to use a social-ecological model ${ }^{24}$ to examine the relationship between context-specific measures of the physical and social environment and children's independent mobility to and from each of the following local destinations: school (a non-discretionary destination), friend's house, park, local shop (discretionary destinations), and overall. We hypothesized that destination-specific features of the physical environment (e.g., presence, type and distance to parks) would be associated with independently mobility to that particular destination (i.e., a local park). 
73

74

75

\section{Methods}

\section{Sample and procedure}

The sample included parents participating in the RESIDential Environments Project (RESIDE). RESIDE commenced in 2003, and is a longitudinal natural experiment of 1813 people building homes in 73 new housing developments across metropolitan Perth, Western Australia. ${ }^{25}$ Details of the RESIDE study recruitment and design are described elsewhere. ${ }^{25}$ Briefly, participants moving to a development were invited to participate by the state water authority following a land transfer transaction. The following eligibility criteria were applied: English proficiency; $\geq 18$ years; intention to relocate by December 2005; and willingness to complete surveys four times over seven years. Participants were recruited by telephone and one adult from each household randomly selected. Participants were surveyed four times: before relocation ( $T 1$ - n=1813); then approximately one (T2 - $\mathrm{n}=1467)$, three $(\mathrm{T} 3$ - $\mathrm{n}=1230)$ and seven $(\mathrm{T} 4-\mathrm{n}=565)$ years after moving house. This sample was selected from all parents $(n=305)$ who provided data on their children's independent travel at the fourth time point (i.e., T4, Feb 2011-Mar 2012). A total of 181 children who were aged 8-15 years were included. If there were more than one child within this age range in the household, the youngest was included. This age range was selected because it represents when children may be given licenses to move independently around their neighborhood. ${ }^{1}$ The University of Western Australia’s Human Research Ethics Committee provided ethics approval.

\section{Measures}

Independent mobility measure: Parents reported whether their child was allowed to walk or cycle alone or with other children (without an adult) to or from four neighborhood destinations: school; friends or family house; park, oval or sporting field; and local shop (e.g., deli, newsagent). ${ }^{26}$ Children who were independently mobile to $\geq 3$ destinations were coded as having 'overall' independent mobility. 
Physical environment measures: Geographic Information Systems (GIS) software was used to

calculate objective measures of the physical environment within a $1600 \mathrm{~m}$ road network buffer

around each participant's home. ${ }^{27}$ Objective measures of the neighborhood environment were

matched to three (park, school and shop) of the four destinations of interest (this was not possible

for 'friend's house' as an address was not recorded).

count of parks, count of school grounds (ovals, sport and play spaces owned/adjacent to school), objective measures of park attributes such as the presence of irrigated lawns, walking paths, trees, sporting facilities, amenities, water features, lighting). ${ }^{29}$ Park attributes were determined by remote sensing methods (Google Earth) using the Public Open Space Desktop Auditing Tool (POSDAT), which has been shown to be a valid and reliable tool for assessing park quality. ${ }^{30}$ We hypothesized that larger parks have more attributes and thus children are more likely to independently travel to these destinations compared with smaller parks.

School-related variables including count of primary schools and the presence of secondary schools were determined using GIS (data provided by the Western Australian Department of Education and Department of Planning). We calculated the presence of shops for daily living (i.e., deli, general store, supermarket, produce market, gasoline station, shopping center) using data from a 
volume (number of vehicles/day). ${ }^{31}$ The ratio of the total length of heavy road volume types by the total length of all road volume types was determined.

Social environment measures: Parent-report measures of neighborhood problems included scales measuring poor neighborhood maintenance (e.g., littering and dumping of rubbish in public areas); social incivilities (e.g., using or selling drugs); graffiti and vandalism; property crime (e.g., household burglary); violent crime (e.g., domestic violence); and two single items of loitering teenagers in public places and dangerous or drink driving. All scales/items were rated on a fourpoint scale (1=not a problem, 4=significant problem) and then dichotomized, with respondents reporting one or more items in the scale as a 'moderate problem' classified as perceiving a problem. Details of these measures are reported elsewhere. ${ }^{32}$

A measure of how safe the neighborhood environment was for children to walk or cycle around the neighborhood without adult accompaniment was based on existing items ${ }^{33}$ that captured parent perceptions of: parks unsafe; not enough footpaths (2 item sub-scale); too much traffic; (single item) and high level of crime risk or abduction make it difficult for children to safely move around their neighborhood without adult supervision (2 item sub-scale). The two sub-scales and the single item were rated on a five-point scale (1=strongly disagree, $4=$ strongly agree) and then dichotomized and combined into an 'unsafe environment' scale (range $0-3$; scores $\geq 1=$ unsafe environment). Single items (5 point Likert scale dichotomized to agree vs. disagree) were used to measure poor collective efficacy ('People in the neighborhood don't look out for children who move around the area without adult supervision'), and poor parenting social norms ('Parents shouldn’t let primary school age children move to and from places without adult supervision'). ${ }^{33}$

\section{Statistical analyses}


Logistic regression models adjusting for child age, gender and siblings, and parent age, gender and education, were used to separately examine the relationship between each objective physical environment and each parent perceived social environment variable and independent mobility to each of the four destinations and overall independent mobility. All physical and social environment variables significant at $p \leq 0.1$ were then included in a multivariable logistic regression model.

\section{Results}

The mean age of children was 10.7 (SD 2.1) years and 45\% were boys. Overall, 22\% of children did not have a sibling, 35\% had a younger sibling (0-7 years), and 56\% had an older sibling (8-17 years) (Supplementary Table 1). Thirty percent of children were independently mobile to and from school, $40 \%$ to a friend's or another family member's house, $48 \%$ to a park, oval or sporting field, $30 \%$ to the local shop and $29 \%$ to at least three of these local destinations (i.e., 'overall') (Table 1).

In multivariable models adjusting for child and parent socio-demographic and all physical and social environment variables significant at $p \leq 0.1$ (see Supplementary Table 2), parent perception of an unsafe neighborhood for children to move around independently significantly decreased the odds of being independently mobile to school (OR=0.25; 95\% CI=0.09-0.70) and overall (OR=0.21; 95\% $\mathrm{CI}=0.06-0.70$ ) (Table 2). If parents perceived that parenting social norms were unsupportive of independent mobility, the odds of their child's independent mobility to the local park (OR=0.64; 95\% $\mathrm{CI}=0.42-0.97)$ and shop $(\mathrm{OR}=0.56$; $95 \% \mathrm{CI}=0.34-0.91)$ significantly decreased. None of the perceived neighborhood problems variables (e.g., social incivilities, violent crime, loitering teenagers in public places, dangerous or drink driving) retained significance in the multivariable models. 
172 A number of objectively measured physical environment variables were significantly $(\mathrm{p}<0.05)$

173

174

175 associated with independent mobility to specific neighborhood destinations (Table 2); increasing access to local school grounds was associated with reduced independent mobility to the park (OR=0.77; 95\% CI=0.62-0.96); increasing distance to the closest large sized park was associated with reduced independent mobility to the park and school $(\mathrm{OR}=0.86 ; 95 \% \mathrm{CI}=0.77-0.95, \mathrm{OR}=0.88$; 95\% CI=0.79-0.99, respectively), and increasing distance to the closest small sized park was associated with reduced independent mobility to the park (OR=0.85; 95\% CI=0.76-0.96). A sensitivity analysis (results not shown) to determine if there were any changes in the effects of physical environment variables before and after adjusting for the social environment variables revealed that there was no change and that the same physical environment variables were independently associated with independent mobility regardless of adjustment for social environment variables.

\section{Discussion}

This study examined the effect of physical and social environment features on children's independent mobility to a number of local destinations (school, park, local shop and friend's house). After adjustment for child and parent socio-demographic variables, parent perceived contextspecific measures of the social environment (i.e., neighborhood safety and parenting social norms related to children's independent movement in the neighborhood) were consistently associated with independent mobility to each destination, except a friend's house. Objective neighborhood physical environment features were associated with independent mobility but were dependent on the destination of interest.

Objectively measured context-specific features of the physical environment were associated with children's independent mobility and varied according to the destination examined. Previous studies 

show that living nearer a park is positively associated with independent mobility ${ }^{4,12,13}$ and our findings support this; independent mobility to a local park decreased as the distance to both the closest small and large sized park increased, even after adjustment for all other factors. Our findings also suggest that access to both small and larger sized local parks is important for encouraging children's independent mobility. To date, the influence of park size has been primarily limited to adult physical activity outcomes, ${ }^{34}$ or considered in the context of recreational planning and public open space strategies. ${ }^{35}$ Most public open space planning guidelines acknowledge the importance of providing different sized parks within local catchment areas, ${ }^{36}$ however the influence of park proximity and size on children's independent travel remains relatively unknown. Further research is warranted to guide urban green planners and developers on the importance of access, size and attributes of local parks for children's independent mobility, physical activity and other health and development outcomes.

\section{Our findings highlight the need to consider the social and physical environment influences on} independent travel to school and individual discretionary destinations (friend's house, park, shops) separately. ${ }^{22}$ Somewhat counter intuitively, increased availability of local school grounds was associated with reduced independent mobility to a local park. It may be that parents are less inclined to allow their children to travel independently to the local park if there is a more familiar or child orientated school oval or playground nearby. These findings indicate the need for school grounds to be accessible out of school hours as they provide an important local destination that children can independently travel to and from. Unfortunately this appears at odds with trends, particularly in Australia, towards fencing off and gating of school grounds. ${ }^{37}$

A number of studies have examined objectively measured physical environment correlates of active travel to school. ${ }^{38,39}$ We observed that independent mobility to school decreased with increasing 
distance to the closest large sized park. It is likely that having destinations such as parks en route to and from school provides children with safe places to stop and play as well as cut-throughs away from the main roads thus reducing their exposure to traffic. ${ }^{13,17,40}$ Future studies should explore the multiple built influences on children's independent mobility when more than one destination is visited in a single trip.

In the final multivariate model the only factor significantly associated with independent mobility to a friend's house was child age. It is possible that the other variables may have been statistically significant had we had a larger sample size and hence, they could be considered in future studies. However, it is also possible that independent travel to a friend's house involves a child travelling to a familiar local destination (i.e., one regularly visited) along a familiar route and in a familiar neighborhood. Thus parents may have fewer concerns. Moreover, compared with other destinations, parents can generally easily confirm whether or not their child has arrived safely and this may help to alleviate some of their concerns about the environment being unsafe and poor social norms amongst parents about allowing children to independently travel.

Aspects of the social environment were also important for children's independent mobility. In the final models only context-specific measures of how safe the neighborhood was for children to move independently and unsupportive parenting social norms about children children’s independent movement were associated with reduced independent mobility to each of the destinations (except friend's house) and overall. Parent perceptions of neighborhood safety including safety from traffic and stranger danger are significantly associated with children’s physical activity, ${ }^{41,42}$ active school transport ${ }^{38}$ and overall independent mobility. ${ }^{41,43} 44$ Our findings confirm that parents who perceive the neighborhood environment as unsafe for children to move around independently are less likely to grant their children licenses to independently travel to a number of different local destinations. 
248 While it appears parent's increased concerns about traffic danger may correspond to evidence of 249 children being at greater risk from traffic accidents, ${ }^{45}$ concerns about stranger danger have been 250 shown to be substantially unfounded ${ }^{46}$ and largely fuelled by a pervasive culture of parental fear 251 and over-protection. ${ }^{47}$ Moreover, parent's perceptions of neighborhood safety may contribute to a 252 social norm that parents shouldn't allow their children (especially those still attending primary 253 school) to move to and from places without adult supervision (i.e., that responsible parenting 254 equates to constant supervision of children). ${ }^{12}$ These social norms can be reinforcing and may 255 supersede any benefits arising from a positive collective efficacy surrounding children moving 256 around the neighborhood independently. Strategies aimed at improving the quality of the local 257 physical environment as well as community level indicators such as sense of community and social 258 capital, ${ }^{12,48}$ may improve parent perceptions of the local neighborhood and its residents and increase 259 children's opportunities to develop independent mobility.

Overall, our findings highlight that the social environment (e.g., parent perceived safety and social norms) influences children’s independent mobility regardless of the destination being visited. Programs aimed at educating parents about the real (from actual crime data) versus perceived safety concerns about children travelling independently around the neighborhood are required. ${ }^{49}$ These programs should also emphasize the child benefits derived from developing independence and address the issues of parental peer pressure to constantly supervise children and an underlying riskaverse culture. ${ }^{50-52}$ Whole of community approaches to improve sense of community and social capital may help to reverse social norms associated with the restriction of children's independent mobility by creating neighborhoods where people look out for children and support the development of their independence. ${ }^{50,53}$ Our findings also highlight that the physical environment is associated with independent mobility to neighborhood destinations even after adjusting for socio- 
demographic and social environment factors. Our study appears to be one of the first to observe that the influence of objectively-measured physical environment on children's independent mobility is specific to the destination being visited. For example, access to different types (parks and school grounds) and sizes (small and large) of urban green spaces was associated with children's independent mobility to a park. A combined strategies approach is required to provide children with access to a variety of safe neighborhood destinations, allay parent safety concerns and educate children about safely navigating their neighborhoods independently.

Study Limitations: The generalizability of the findings may have been compromised because RESIDE participants live in relatively new housing developments on the urban fringe and thus may not be representative of all parents and children. This study relied on parent-report measures of independent mobility and the social environment. Future studies should consider including childreport measures of independent mobility and their perceptions of the environment as well as objective measures of the social environment (e.g., crime rates and child-related offences). Furthermore, our study did not include all features of the perceived social environment considered important for children's independent mobility. Future empirical studies should also measure the influence of peers, parent level of local walking, dog ownership, parent and child perceptions of appropriate destinations and the value of these local destinations. ${ }^{54-56}$ However, context-specific and objectively measured physical environment features were strengths of this study. Another strength of this study was its investigation of the social and physical environment features associated with independent mobility to a number of different local destinations. Future studies should use Global Position Systems (GPS) to objectively measure destinations children visit along with a self-report measure (SMS or an app) to determine if the travel has been unaccompanied by adults. ${ }^{57,58}$ 
296

While this study appears to among the first studies to empirically investigate the physical (and social) environment factors associated with children's independent mobility to a friend's house and local shop, no objectively measured physical environment variables in the final models were significantly associated with independent mobility to these destinations. This may be due to a lack of a context-specific measure for friend's house (e.g., distance to closest friend's house) and the sample size. Future studies should include objective measures of street connectivity, traffic exposure and intersection crossings and investigate the relative influence of social and physical environment factors on independent mobility to different local destinations (stratified by gender) using context-specific objective measures and larger sample sizes.

Conclusion: Parent perceptions of neighborhood safety and parenting social norms were consistently associated with independent mobility to all of the specific destinations examined, except a friend's house. Associations between objective physical environment features and independent mobility were dependent on the destination of interest and remained significant after adjusting for social environment factors. Access to different sized parks as well as school grounds were associated with independent mobility to a park, highlighting that access to different types of urban green spaces is important for children's independent mobility to key non-school destinations and that the influence of physical environment factors on children's independent mobility is specific to the destination being visited. Future research should examine correlates of independent mobility to individual destinations other than school using objective context-specific measures of the physical and social environment. Further evidence of the influence of the physical environment on children's independent mobility to specific destinations when more than one destination is visited in a single commute is also required. 
320 Acknowledgements: The first author is supported by a National Health and Medical Research

321 Council (NHMRC)/National Heart Foundation Early Career Fellowship (1036350), the fifth author

322 (21363) and eighth author (20693) are supported by a Healthway Health Promotion Research

323 Fellowships and the final author is supported by an NHMRC Principal Research Fellow Award 324 (1004900). The authors gratefully acknowledge the Geographic Information Systems team (XXX, $325 \mathrm{XXX}, \mathrm{XXX}, \mathrm{XXX}$ ) for their assistance in the development of the GIS measures used in this study.

326 XXX coordinated data collection and XXX provided administrative assistance. The Western

327 Australian Land Information Authority (@2003), Western Australian Department of Planning, 328 Department of Transport and Department of Education, and Sensis Pty Ltd provided the spatial 329 data.

331 Funding source: The RESIDE II Study was funded by a grant from the Western Australian Health 332 Promotion Foundation (18921). 


\section{References}

1. Hillman M, Adams J, Whitelegg J. One False Move: A Study of Children's Independent Mobility. London: PSI publishing; 1990.

2. Schoeppe S, Duncan MJ, Badland H, Oliver M, Curtis C. Associations of children's independent mobility and active travel with physical activity, sedentary behaviour and weight status: A systematic review. J. Sci. Med. Sport. 2013;16(4):312-319.

3. Page A, Cooper A, Griew P, Davis L, Hillsdon M. Independent mobility in relation to weekday and weekend physical activity in children aged 10-11 years: The PEACH Project. Int. J. Behav. Nutr. Phys. Act. 2009;6:2.

4. Prezza M, Pilloni S, Morabito C, Sersante C, Alparone FR, Giuliani MV. The influence of psychosocial and environmental factors on children's independent mobility and relationship to peer frequentation. J. Community. Appl. Soc. Psychol. 2001;11(6):435-450.

5. Broberg A, Salminen S, Kyttä M. Physical environmental characteristics promoting independent and active transport to children's meaningful places. Appl. Geogr. 2013;38:4352.

6. Carver A, Timperio AF, Crawford DA. Young and free? A study of independent mobility among urban and rural dwelling Australian children. J. Sci. Med. Sport. 2012;15(6):505510.

7. Rissotto A, Tonucci F. Freedom of movement and environmental knowledge in elementary school children. J. Environ. Psychol. 2002;22(1-2):65-77.

8. Fyhri A, Hjorthol R, Mackett RL, Fotel TN, Kyttä M. Children's active travel and independent mobility in four countries: Development, social contributing trends and measures. Transport Policy. 2011;18(5):703-710.

9. McDonald NC. Active transportation to school: Trends among U.S. schoolchildren, 19692001. Am. J. Prev. Med. 2007;32(6):509-516. 
10. Karsten L. It all used to be better? Different generations on continuity and change in urban children's daily use of space. Children's Geographies. 2005;3(3):275-290.

11. Mackett RL. Children's travel behaviour and its health implications. Transport Policy. 2013;26:66-72.

12. Alparone FR, Pacilli MG. On children's independent mobility: The interplay of demographic, environmental, and psychosocial factors. Children's Geographies. 2012;10(1):109-122.

13. Mackett R, Brown B, Gong YI, Kitazawa KAY, Paskins J. Children's independent movement in the local environment. Built. Environ. 2007;33(4):454-468.

14. Zwerts E, Allaert G, Janssens D, Wets G, Witlox F. How children view their travel behaviour: A case study from Flanders (Belgium). J. Transp. Geogr. 2010;18(6):702-710.

15. Valentine G, McKendrck J. Children's outdoor play: Exploring parental concerns about children's safety and the changing nature of childhood. Geoforum. 1997;28(2):219-235.

16. McMillan TE. Urban Form and a Child's Trip to School: The current literature and a framework for future research. J. Plann. Lit. 2005;19(4):440-456.

17. Villanueva K, Giles-Corti B, Bulsara M, et al. Where do children travel to and what local opportunities are available? The relationship between neighborhood destinations and children’s independent mobility. Environ. Behav. 2013;45(6):679-705.

18. Sampson RJ, Morenoff JD, Gannon-Rowley T. Assessing "Neighborhood Effects": Social processes and new directions in research. Ann. Rev. Sociol. 2002;28:443-478.

19. Giles-Corti B, Salmon J. Encouraging children and adolescents to be more active. BMJ. 2007;335(7622):677-678.

20. Carver A, Timperio A, Crawford D. Parental chauffeurs: What drives their transport choice? J. Transp. Geogr. 2013;26:72-77. 
21. Jago R, Baranowski T. Non-curricular approaches for increasing physical activity in youth: a review. Prev. Med. 2004;39(1):157-163.

22. Steinbach R, Green J, Edwards P. Look who's walking: Social and environmental correlates of children's walking in London. Health Place. 2012;18(4):917-927.

23. Ewing R, Schroeer W, Greene W. School location and student travel analysis of factors affecting mode choice. Transportation Research Record. 2004;1895(1):55-63.

24. Stokols D. Translating social ecological theory into guidelines for community health promotion. Am. J. Health Promot. 1996;10(4):282-298.

25. Giles-Corti B, Knuiman M, Timperio A, et al. Evaluation of the implementation of a state government community design policy aimed at increasing local walking: Design issues and baseline results from RESIDE, Perth Western Australia. Prev. Med. 2008;46(1):46-54.

26. Martin K, Rosenberg M, Miller M, et al. Move and Munch Final Report: Trends in physical activity, nutrition and body size in Western Australian children and adolescents: the Child and Adolescent Physical Activity and Nutrition Survey (CAPANS) 2008. Government of Western Australia. 2008.

27. Christian H, Knuiman M, Bull F, et al. A new urban planning code’s impact on walking: The Residential Environments Project. Am. J. Public Health. 2013;103(7):1219-1228.

28. Public Open Space (POS) Tool. Centre for the Built Environment and Health, School of Population Health, The University of Western Australia; 2013.

29. Giles-Corti B, Broomhall $\mathrm{MH}$, Knuiman $\mathrm{M}$, et al. Increasing walking: How important is distance to, attractiveness, and size of public open space? Am. J. Prev. Med. 2005;28(Suppl 2):S169-S176.

30. Edwards N, Hooper P, Trapp GSA, Bull F, Boruff B, Giles-Corti B. Development of a Public Open Space Desktop Auditing Tool (POSDAT): A remote sensing approach. Appl. Geogr. 2013;38:22-30. 
31. Main Roads Western Australia Functional Road Hierarchy. http://www2mainroadswagovau/NR/rdonlyres/7DE6FC8F-A376-49FE-9B9911BA1F5B3D54/442/frh_criteria3pdf. 2007. Accessed 1 Aug 2012.

32. Foster S, Giles-Corti B, Knuiman M. Neighbourhood design and fear of crime: A socialecological examination of the correlates of residents' fear in new suburban housing developments. Health. Place. 2010;16:1156-1165.

33. Australian Council for Educational Research. VicHealth Health Sporting Environments Survey 2009. CATI Questionnaire v13. 20 Oct 2009: CIM; 2009.

34. Kaczynski AT, Henderson KA. Environmental correlates of physical activity: A review of evidence about parks and recreation. Leisure. Sci. 2007;29(4):315-354.

35. Commission for Architecture and the Built Environment and the Greater London Authority. Open Space Strategies. Best Practice Guidance. London, UK: Commission for Architecture and the Built Environment - CABE Space;2009.

36. NSW Government Department of Planning. Recreation and Open Space Planning Guidelines for Local Government. NSW, Australia 2013.

37. Martin K, Wood L. 'We live here too'.... What makes a child friendly neighbourhood? In: Elizabeth Burton RD-C, and Cary Cooper, ed. Wellbeing: A Complete Reference Guide: Wiley-Blackwell; 2012.

38. Trapp G, Giles-Corti B, Christian H, et al. Increasing children's physical activity: Individual, social, and environmental factors associated with walking to and from school. Health Educ. Behav. 2011;39:172-182.

39. Panter J, Jones A, Van Sluijs E. Environmental determinants of active travel in youth: A review and framework for future research. Int. J. Behav. Nutr. Phys. Act. 2008;5(3):34.

40. Villanueva K, Giles-Corti B, Bulsara M, et al. How far do children travel from their homes? Exploring children's activity spaces in their neighborhood. Health. Place. 2012;18:263-273. 
432

41. Giles-Corti B, Kelty SF, Zubrick SR, Villanueva KP. Encouraging walking for transport and physical activity in children and adolescents: How important is the built environment? Sports. Med. 2009;39(12):995-1009.

42. Jago R, Thompson J, Page A, Brockman R, Cartwright K, Fox K. Licence to be active: Parental concerns and 10-11-year-old children's ability to be independently physically active. J. Public. Health. 2009;31(4):472-477.

43. Fyhri A, Hjorthol R. Children's independent mobility to school, friends and leisure activities. J. Transp. Geogr. 2009;17(5):377-384.

44. Santos MP, Pizarro AN, Mota J, Marques EA. Parental physical activity, safety perceptions and children's independent mobility. BMC public health. 2013;13(1):584.

45. UNICEF. A League Table of Child Deaths by Injury in Rich Nations. Florence: UNICEF Innocenti Research Centre;2001. 8885401716.

46. Foster S, Villanueva K, Wood L, Christian H, Giles-Corti B. The impact of parental fear of strangers and informal social control on children’s independent mobility. Health. Place. 2014;26(60-68).

47. Shutt JE, Miller JM, Schreck CJ, Brown NK. Reconsidering the leading myths of stranger child abduction. Criminal Justice Studies. 2004;17(1):127-134.

48. Zubrick S, Wood L, Villanueva K, Wood G, Giles-Corti B, Christian H. Nothing But Fear Itself: Parental Fear As a Determinant Impacting on Child Physical Activity and Independent Mobility. Melbourne, Australia: Victorian Health Promotion Foundation;2010.

49. Mammen G, Faulkner G, Buliung R, Lay J. Understanding the drive to escort: a crosssectional analysis examining parental attitudes towards children's school travel and independent mobility. BMC Public Health. 2012;12(1):862-873.

50. Furedi F, Füredi F. Paranoid parenting: Why ignoring the experts may be best for your child: Continuum London; 2008. 
457

51. Lorenc T, Brunton G, Oliver S, Oliver K, Oakley A. Attitudes to walking and cycling among children, young people and parents: a systematic review. J. Epidemiol. Community Health. 2008;62(10):852-857.

52. Valentine G. ” Oh Yes I Can.”“Oh No You Can't”: Children and parents' understandings of kids' competence to negotiate public space safely. Antipode. 1997;29(1):65-89.

53. Witten K, Kearns R, Carroll P, Asiasiga L, Tava'e N. New Zealand parents' understandings of the intergenerational decline in children's independent outdoor play and active travel. Children's Geographies. 2013;11(2):215-229.

54. Kraftl P, Christensen P, Horton J, Hadfield-Hill S. Living on a building site: Young people’s experiences of emerging ‘Sustainable Communities’ in England. Geoforum. 2013;50:191199.

55. Ergler CR, Kearns RA, Witten K. Seasonal and locational variations in children's play: implications for wellbeing. Soc. Sci. Med. 2013;91:178-185.

56. Mackett RL, Paskins J. Children's physical activity: The contribution of playing and walking. Child Soc. 2008;22(5):345-357.

57. Bates B, Stone MR. Measures of outdoor play and independent mobility in children and youth: A methodological review. J. Sci. Med. Sport. 2014: In press.

58. Badland HM, Oliver M, Duncan MJ, Schantz P. Measuring children's independent mobility: comparing objective and self-report approaches. Children's Geographies. 2011;9(2):263. 
477 Table 1: Physical and social environment and independent mobility characteristics of sample

$\mathrm{N}(\%)$ or

mean (SD)

\section{Social environment factors}

Poor neighborhood maintenance

$70(38.7)$

Social incivilities

$46(25.4)$

Graffiti and vandalism

Property crime

Loitering teenagers in public places

Dangerous or drink driving

Violent crime

Unsafe environment for children to independently move around

$62(34.3)$

neighborhood

Poor collective efficacy for children to independently move around

neighborhood

Parenting social norm doesn't support children to independently move

$84(46.4)$

around neighborhood

\section{Physical environment factors}

Count of primary schools, mean (SD)

Presence of Secondary school

Count of school grounds, mean (SD)

Count of parks, mean (SD)

Distance to closest park (any size category) (m), mean (SD)

Distance to closest pocket size park (m), mean (SD)

Distance to closest small size park (m), mean (SD)

511.2 (396.0) 
Distance to closest medium size park (m), mean (SD)

$728.9(514.7)$

Distance to closest large/district size park (m), mean (SD)

$595.1(467.8)$

Attractiveness score of closest park, mean (SD)

$37.6(14.2)$

Presence of playground at closest park

$101(55.8)$

Presence of shops for daily living (convenience stores)

$80(44.2)$

Traffic exposure

$16.7(10.0)$

\section{Independent Mobility}

Independently mobile to and from:

School

Friends/family house

Park/oval/sporting field

$87(48)$

Local shop

$55(30)$

Overall Independent Mobility ${ }^{\mathrm{a}}$

53 (29)

${ }^{\mathrm{a}}$ Independently mobile to and from three or all four of the destinations 


\begin{tabular}{|c|c|c|c|c|c|}
\hline & School & $\begin{array}{l}\text { Friends or family } \\
\text { house }\end{array}$ & $\begin{array}{l}\text { Park/oval or sporting } \\
\text { field }\end{array}$ & Local shop & $\begin{array}{c}\text { Overall Independent } \\
\text { Mobility }^{\mathrm{a}}\end{array}$ \\
\hline & OR $(95 \% \mathrm{CI})$ & OR (95\% CI) & OR $(95 \% \mathrm{CI})$ & OR $(95 \% \mathrm{CI})$ & OR $(95 \% \mathrm{CI})$ \\
\hline \multicolumn{6}{|l|}{ Socio-demographic factors } \\
\hline Child age & $1.61(1.28-2.02)^{* * *}$ & $2.02(1.58-2.58)^{* * *}$ & $1.94(1.48-2.56)^{* * *}$ & $2.64(1.91-3.64)^{* * *}$ & $2.45(1.82-3.30)^{* * *}$ \\
\hline Child gender (Ref=girl) & $0.76(0.34-1.67)$ & $1.61(0.73-3.58)$ & $3.78(1.53-9.32) * * *$ & $2.40(0.94-6.10)^{*}$ & $2.10(0.83-5.30)$ \\
\hline Parent age & $0.94(0.87-1.02)$ & $0.99(0.92-1.06)$ & $0.98(0.90-1.07)$ & $1.02(0.93-1.12)$ & $1.00(0.91-1.09)$ \\
\hline Parent gender (Ref=male) & $1.64(0.65-4.12)$ & $1.23(0.53-2.87)$ & $1.16(0.46-2.95)$ & $1.83(0.65-5.17)$ & $1.87(0.68-5.14)$ \\
\hline $\begin{array}{l}\text { Parent education (Ref=Bachelor } \\
\text { degree or higher) }\end{array}$ & 1.00 & 1.00 & 1.00 & 1.00 & 1.00 \\
\hline Trade/Certificate/Diploma & $2.56(0.92-7.13) *$ & $1.00(0.40-2.56)$ & $1.82(0.63-5.26)$ & $1.11(0.37-3.31)$ & $0.70(0.24-2.06)$ \\
\hline Secondary school & $1.87(0.65-5.33)$ & $0.67(0.24-1.83)$ & $1.00(0.32-3.23)$ & $0.53(0.16-1.79)$ & $0.33(0.10-1.12)^{*}$ \\
\hline Older sibling of same gender & $2.63(1.09-6.32)^{* * *}$ & - & - & $6.17(2.07-18.34)^{* * *}$ & $2.77(1.02-7.52)^{* *}$ \\
\hline
\end{tabular}


Number of older siblings

(Ref=none)

one

$\geq$ two

\section{Physical environment factors}

Count of Primary schools

Presence of Secondary schools

Count of school grounds

Distance to closest small size

park (100m), mean (SD)

Distance to closest large/district

$0.89(0.79-0.99) * *$

size park (100m), mean (SD)

Attractiveness score of closest

$1.01(0.98-1.05)$

park

Presence of shops for daily

living (convenience stores)

$1.46(0.62-3.46)$
1.00

1.00

$2.24(0.94-5.35)^{*}$

$0.75(0.22-2.60)$

$7.29(2.57-20.68)^{* * *}$

$1.10(0.90-1.36)$

$0.77(0.62-0.96) * *$

$0.85(0.76-0.96) * * *$

$0.86(0.77-0.95)^{* * *}$

$0.52(0.23-1.19)$
$1.05(0.77-1.42)$

$0.93(0.83-1.04)$

$1.59(0.89-2.84)$ 


\section{Social environment factors}

Social incivilities

Loitering teenagers in public

places

Dangerous or drink driving

Violent crime

Unsafe environment for

children to independently move

around neighborhood

Parenting social norm doesn't

support children to

independently move around

neighborhood

$$
0.34(0.09-0.70)
$$

$$
0.38(0.05-3.14)
$$

$0.25(\mathbf{0 . 0 9 - 0 . 7 0 ) * * *} \quad 0.45(0.17-1.20)$

$0.63(0.22-1.80)$

$0.37(0.12-1.16)^{*}$

$0.21(0.06-0.70)^{* *}$
$0.63(0.20-2.01)$

$0.44(0.10-1.92)$

$0.54(0.14-2.11)$

$0.45(0.17-1.20)$

$0.76(0.52-1.12)$

$0.64(0.42-0.97)^{* *}$
$0.56(0.34-0.91)^{* *}$

481 IM=Independent Mobility; Ref=Reference category; ${ }^{*} \mathrm{p} \leq 0.1 ;{ }^{* *} \mathrm{p} \leq 0.05 ; * * * \mathrm{p} \leq 0.01$

$482{ }^{\mathrm{a}}$ Independently mobile to $\geq$ three destinations 


\section{University Library}

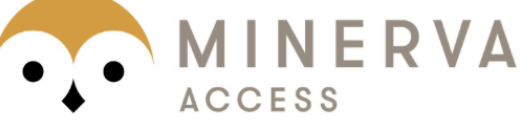

A gateway to Melbourne's research publications

Minerva Access is the Institutional Repository of The University of Melbourne

\section{Author/s:}

Christian, HE;Klinker, CD;Villanueva, K;Knuiman, MW;Foster, SA;Zubrick, SR;Divitini, M;Wood, L;Giles-Corti, B

Title:

The Effect of the Social and Physical Environment on Children's Independent Mobility to Neighborhood Destinations

Date:

2015-06-01

Citation:

Christian, H. E., Klinker, C. D., Villanueva, K., Knuiman, M. W., Foster, S. A., Zubrick, S. R., Divitini, M., Wood, L. \& Giles-Corti, B. (2015). The Effect of the Social and Physical Environment on Children's Independent Mobility to Neighborhood Destinations. JOURNAL OF PHYSICAL ACTIVITY \& HEALTH, 12 (s1), pp.S84-S93. https://doi.org/10.1123/ jpah.2014-0271.

Persistent Link:

http://hdl.handle.net/11343/118592 